\title{
What's Math Got to Do with It?
}

\author{
A Review by Alfred Manaster
}

\author{
What's Math Got To Do With It?: How Teachers \\ and Parents Can Transform Mathematics \\ Learning and Inspire Success \\ Jo Boaler \\ Penguin Books, revised edition, March 2015 \\ Paperback, US $\$ 13.60$ \\ ISBN-13: 978-0-14312-829-8
}

\section{Context}

Why do we want to give all students good opportunities to develop an interest in and to learn mathematics? In the first place, we want to give them the best possible chance to use some mathematical habits of mind in their own lives, to help them make well-thought-out decisions for themselves and for their communities. Secondly, we want them to develop respect for mathematical and scientific methods, thinking, and results; this respect is best developed using some of these tools themselves to answer questions that interest them. This respect, in turn, can be useful in understanding the complexity of contemporary science and in evaluating the arguments of the increasing numbers of deniers of many research-based judgments and recommendations. Thirdly, we want students to have access to as many careers as possible for as long as possible; while only some will choose mathematics or other quantitatively based professions, those choices should not be closed prematurely due to inadequate backgrounds, undeveloped skills,

Alfred Manaster is professor emeritus of mathematics at the University of California, San Diego. His email address is amanaster@ucsd.edu.

For permission to reprint this article, please contact: reprint-permission@ams.org.

DOI: http://dx.doi.org/10.1090/noti1281 misunderstanding of the nature of the fields, or fear of failure. Finally, we have a selfish interest in developing a mathematically and quantitatively literate public: that public is more likely to provide political support for rigorous study of both pure and applied problems.

\section{The Book's Concepts of Mathematics and Mathematics Education}

In the revised edition (March 2015) of What's Math Got To Do With It? How Teachers and Parents Can Transform Mathematics Learning and Inspire Success, Jo Boaler presents important mathematical goals for all students, descriptions of classroom environments and teaching approaches that support those goals, some of the research findings that indicate these approaches work, and examples of problems that parents and teachers can offer to children to engage them in mathematics and strengthen their mathematical backgrounds.

Professor Boaler emphasizes the development of mathematical activities and ways of thinking, but she also recognizes the importance of mathematical techniques and underlying principles. Mathematics is viewed as a sense-making activity. Reasoning is a critical component of the convincing argumentation that is required for understanding. Early on (p. 21), the construction of time-resistant proofs is recognized as what mathematics is "all about."

The book's treatment of problem solving and the ways it should be presented and used is quite compatible with mathematicians' understanding of its nature. Most mathematics can be considered as arising in a context of problem solving. The choice of which problems to work on is motivated by interest and need. Theories are often developed to answer fairly broad questions, while 
theorems are often formulated and proved to solve more specific problems. Problem solving is closely related to making sense and developing convincing arguments. It often starts with formulating a question and then continues with guesses or estimates of possible answers, followed by adjustments and refinements as early approaches fail. A solution is usually a precise answer to the question or a related one, which may be more specific or more general or a reformulation of the original question. To be a solution, the answer must be justified by a complete understanding of how it was found and why, based on a logical analysis, it must be correct. Even though there is usually one answer to the (final) question, there are often many ways to find it and several convincing logical analyses showing that it must be correct.

Formulating and solving problems require the development and use of a variety of representations, including verbal and algebraic languages, pictures, graphs, diagrams, and tables. Finding these representations and using them flexibly but with precision can increase understanding of both the problems and their solutions. It can also help develop generalizations of results and place them in more theoretical contexts.

A theoretical underpinning of the book's approach to mathematical education is that the best (only?) way for students to reach the central goals of mathematical understanding is through experiencing mathematical activities. What constitutes convincing proof (for example) obviously depends upon the audience, but the desire to develop convincing proofs and a yearning for understanding should be stimulated in appropriate ways throughout a child's mathematics experiences. For this to happen, students must have opportunities to work on questions that are meaningful and interesting to them. They must also have the freedom to explore their own ways of finding solutions in a supportive and collaborative environment and to make mistakes and learn from them. They should ask questions and help formulate and reformulate problems, and they should demand fully convincing answers to problems and questions.

To stimulate and maintain interest of all students with their diverse interests and ways of learning, as well as their changing responses to different social and intellectual environments, Professor Boaler calls for a variety of several kinds in mathematics classes and curricula. Effective curricula include problems ranging from long investigations to short questions. The contexts vary from applied realistic settings to abstract pure ones. Students are given ample opportunities to work alone and also to collaborate with others.

In addition to working on challenging problems and developing convincing justifications for their solutions, students must also have ample opportunities to encounter mathematical ideas, to reflect upon them, and to explore how they are related to one another. Projects must be carefully chosen "to interest the students and to provide opportunities for learning important mathematical concepts and methods" (p. 74). Learning mathematics includes discussing those concepts and methods (after they have been developed in meaningful contexts), exploring other ways of using them, and comparing them to each other.

Professor Boaler's vision for mathematics instruction follows naturally from her goals for the mathematics that students should learn. The book does not merely present this vision but also summarizes research findings that support the effectiveness of the instructional approaches she recommends. It includes extended discussion of two longitudinal studies she conducted comparing students taught using the kinds of instruction she advocates with students taught in more traditional classes: one study compared students in two United States high schools, the other students in two English middle schools. In both studies she found that students exposed to rich educational experiences made significantly greater advances on standard tests. They also gained much more self-confidence in their ability to learn mathematics and developed an enjoyment of the subject. In the US study, 41 percent of the seniors in the high school that had developed a "new approach" (compatible with Professor Boaler's recommendations) were enrolled in advanced precalculus or calculus courses; in the nearby high school, whose students entered high school with higher achievement levels but were taught mathematics using traditional methods, only 23 percent of seniors were in precalculus or calculus courses. In the study of two English middle schools, she found that eight years later, students who had been in the more projectbased classes were working in more highly skilled or professional jobs than those who attended the more traditional classes, even though the levels of the parents' jobs in the two schools had been equal. In addition, the first group of students saw how they applied the mathematical reasoning skills in their lives and careers, while those in the second group were more likely to wonder why they had been forced to learn mathematics and why they couldn't use it.

\section{Concerns and Recommendations}

Boaler does not explicitly mention the abstract nature of mathematical content. Doing so might have been helpful to some readers, since the intended audience includes parents with little understanding of mathematics. Recognizing that abstraction enables the certainty of many mathematical results might help readers understand the power and the limitations of mathematics and mathematical techniques. Otherwise, some may be more dismissive of mathematics, since they are familiar with many 
more concrete contexts where complete precise answers to questions are not possible.

What's Math Got To Do With It? calls for dramatically changing traditional US mathematics classes. The reasonableness of the author's goals for students and the good fit between those goals and the approaches described provide much support for that call. Her recommendation is supported further by the evidence in the author's research and other research she cites. There are questions that also need to be considered before fully embracing what is referred to at the end of the book as a revolution. As Professor Boaler indicates, the classrooms she envisions (and has seen) are much more chaotic than traditional classrooms, so that a teacher has to learn how to lead and teach in a very different way, one that may be uncomfortable for many at first. Teachers tend to teach the way they have been taught, so effective change may have to occur more slowly than Professor Boaler hopes. This point is reinforced by the need for teachers to be open to and able to build upon the wide variety of approaches that their students will take in solving problems. This, in turn, requires a broader and deeper subject matter knowledge for teachers than that required for the more traditional mathematics instruction. So, teacher education will need to address both class management and subject matter knowledge from different, probably richer, perspectives.

Another issue not addressed in the book concerns prerequisites for students enrolling in mathematics courses. The book includes compelling arguments for avoiding tracking students at an early stage, but the question of when to require students to have adequate background knowledge for the benefit of all the students in a course is neither raised nor answered. My experience has been that it is much more difficult to teach most undergraduate courses to a class with widely divergent mathematical backgrounds.

In my opinion, any mathematician who wants to support and improve precollegiate mathematics education will be more effective in doing so after carefully considering Professor Boaler's work and recommendations reported in What's Math Got To Do With It? Awareness of the effects of different kinds of classroom experiences on students provides an essential perspective for helping schools, districts, states, and the nation better support development of mathematical understanding for all students. The book also seems very valuable for mathematicians who teach courses designed for preservice or in-service teachers, partly so that they can begin exposing students to the kinds of learning experiences and instructional settings that have been shown to be so powerful for many elementary and secondary students.

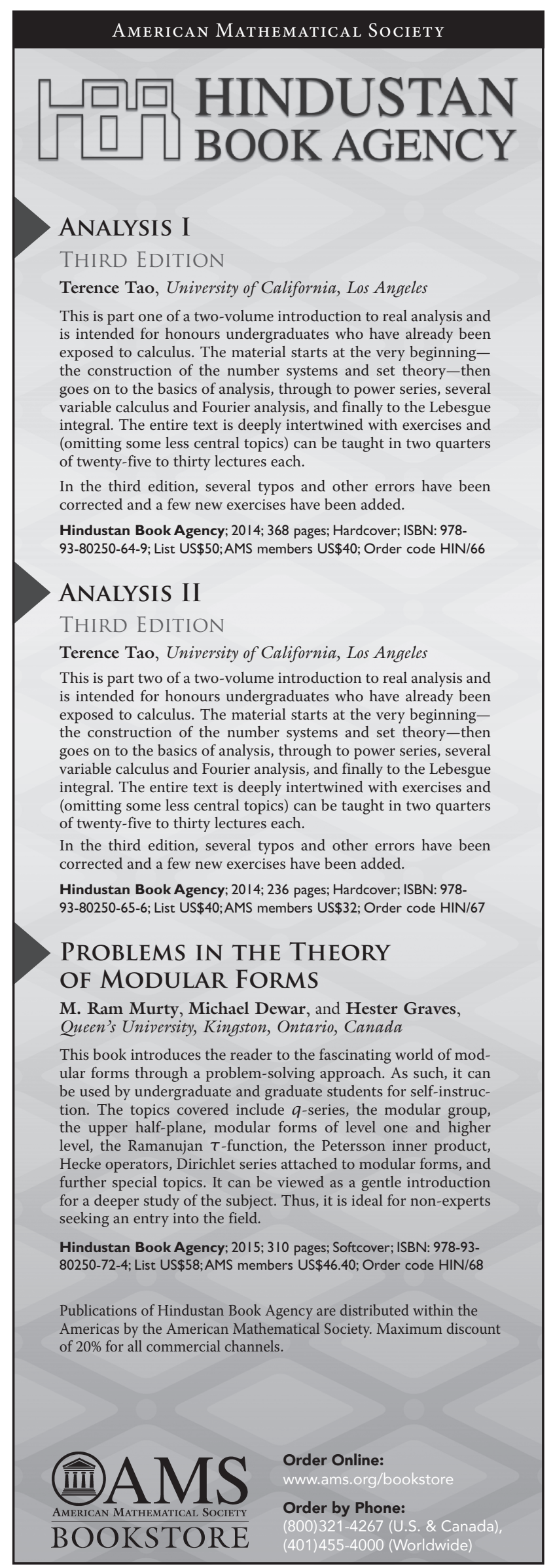

